\title{
Therapeutic prediction of HIV-1 DNA decay: a multicenter longitudinal cohort study
}

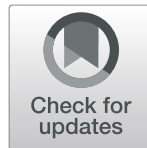

Yongsong Yue ${ }^{1,2,3 \dagger}$, Yijia $\mathrm{Li}^{1,4 \dagger}$, Yizhi Cui ${ }^{5 \dagger}$, Nidan Wang ${ }^{1,2}$, Yunda Huang ${ }^{6,7}$, Wei Cao ${ }^{1,2}$, Yang Han ${ }^{1,2}$, Ting Zhu ${ }^{1,2}$, Wei Lyu ${ }^{1,2}$, Jing Xie ${ }^{1,2}$, Xiaojing Song ${ }^{1,2}$, Yanling $\mathrm{Li}^{1,2}$, Tong Wang ${ }^{5^{*}}$, Tuofu Zhu ${ }^{8^{*}}$ and Taisheng $\mathrm{Li}^{1,2^{*}}$ (D)

\begin{abstract}
Background: Factors predicting peripheral blood total HIV-1 DNA size in chronically infected patients with successfully suppressed viremia remain unclear. Prognostic power of such factors are of clinical significance for making clinical decisions.

Methods: Two sets of study populations were included: 490 China AIDS Clinical Trial (CACT) participants (Training cohort, followed up for 144 to 288 weeks) and 117 outpatients from Peking Union Medical College Hospital (PUMCH) (Validation cohort, followed up for more than 96 weeks). All patients were chronically HIV-1-infected and achieved successful HIV-1 plasma RNA suppression within week 48. Total HIV-1 DNA in blood at baseline, 12, 24, 48, 96, 144 and 288 weeks after combined antiretroviral therapy (CART) initiation were quantified. Generalized estimating equations and logistic regression methods were used to derive and validate a predictive model of total HIV-1 DNA after 96 weeks of CART.

Results: The total HIV-1 DNA rapidly decreased from baseline [median $=3.00 \log _{10} \mathrm{copies} / 10^{6}$ peripheral blood mononuclear cells (PBMCs)] to week 24 (median $=2.55 \log _{10}$ copies $/ 10^{6} \mathrm{PBMCs}$ ), and leveled off afterwards. Of the 490 patients who had successful HIV-1 plasma RNA suppression by $96 \mathrm{w}$ post-cART, 92 (18.8\%) had a low total HIV-1 DNA count $\left(<100\right.$ copies $/ 10^{6}$ PBMCs) at week 96 . In the predictive model, lower baseline total HIV-1 DNA [risk ratio (RR) = 0.08 , per $1 \log _{10}$ copies $/ 10^{6}$ PBMCs, $P<0.001$ ] and higher baseline CD4+ T cell count (RR $=1.72$, per 100 cells $/ \mu \mathrm{L}, P<$ 0.001 ) were significantly associated with a low total HIV-1 DNA count at week 96 . In an independent cohort of 117 patients, this model achieved a sensitivity of $75.00 \%$ and specificity of $69.52 \%$.

Conclusions: Baseline total HIV-1 DNA and CD4+ T cell count are two independent predictors of total HIV-1 DNA after treatment. The derived model based on these two baseline factors provides a useful prognostic tool in predicting HIV1 DNA reservoir control during CART.
\end{abstract}

Keywords: HIV-1 DNA, Prediction model, Chronic infection, Combined antiretroviral therapy, CD4

\footnotetext{
*Correspondence: tongwang@email.jnu.edu.cn; tzhu@uw.edu; litsh@263.net Prior presentations: Parts of the data were presented previously at the 22nd International AIDS Conference (July 25, 2018, Amsterdam, Netherlands) ${ }^{\dagger}$ Yongsong Yue, Yijia Li and Yizhi Cui contributed equally to this work. ${ }^{5}$ Key Laboratory of Functional Protein Research of Guangdong Higher Education Institutes, Institute of Life and Health Engineering, College of Life Science and Technology, Jinan University, Guangzhou 510632, China

${ }^{8}$ Department of Laboratory Medicine, School of Medicine, University of Washington, 325 Ninth Ave, Seattle, WA 98104-2499, USA

'Department of Infectious Diseases, Peking Union Medical College Hospital, Chinese Academy of Medical Sciences \& Peking Union Medical College, No. 1 Shuaifuyuan, Wangfujing Street, Beijing 100730, China

Full list of author information is available at the end of the article
}

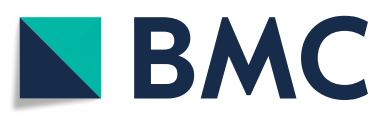

(c) The Author(s). 2021 Open Access This article is licensed under a Creative Commons Attribution 4.0 International License which permits use, sharing, adaptation, distribution and reproduction in any medium or format, as long as you give appropriate credit to the original author(s) and the source, provide a link to the Creative Commons licence, and indicate if changes were made. The images or other third party material in this article are included in the article's Creative Commons licence, unless indicated otherwise in a credit line to the material. If material is not included in the article's Creative Commons licence and your intended use is not permitted by statutory regulation or exceeds the permitted use, you will need to obtain permission directly from the copyright holder. To view a copy of this licence, visit http://creativecommons.org/licenses/by/4.0/ The Creative Commons Public Domain Dedication waiver (http://creativecommons.org/publicdomain/zero/1.0/) applies to the data made available in this article, unless otherwise stated in a credit line to the data. 


\section{Introduction}

A critical goal of antiretroviral therapy is to reduce the size of the total HIV-1 DNA reservoir which poses a major obstacle for HIV-1 eradication [1-3]. Total HIV-1 DNA load has been associated with disease progression, treatment efficacy, and HIV-1 co-morbidities such as HIV-1-associated dementia and malignancy [4-7]. High total HIV-1 DNA levels during cART have been associated with faster viral rebound after structured treatment interruption (STI) [8-10], while low total HIV-1 DNA levels may increase the possibility of prolonged viral remission after cART interruption, which was observed in the Mississippi baby [11] and post-treatment controllers (PTCs) $[12,13]$. In the VISCONTI cohort study, the median total HIV-1 DNA level was near 100 copies $/ 10^{6}$ PBMCs in the 14 PTCs when cART was discontinued, which served as a milestone of relatively successful HIV1 reservoir control, potentially leading to prolonged remission or functional cure [12].

It is generally accepted that early treatment is critical for the viral suppression of PTCs [12]. Numerous studies have investigated factors related to the dynamics of total HIV-1 DNA decay during cART, including treatment initiation time, antiretroviral therapy intensity, demographic data, baseline HIV-1 plasma RNA and DNA, CD4+ and CD8+ cell count and CD4/CD8 ratio. Early initiation of cART during primary infection, low baseline total HIV-1 DNA and high $\mathrm{CD} 4+$ nadir were shown to increase the likelihood of achieving low total HIV-1 DNA outcome [1417]. In addition, a cross-sectional study has reported that $28 \%$ out of 522 patients who are initiated cART during the chronic phase can achieve low total HIV-1 DNA (< 150 copies $/ 10^{6}$ PBMCs) after long-term viral suppression [18]. Thus, as it is associated with ART-free remission, total HIV-1 DNA could serve as a usefully virologic parameter for monitoring therapeutic effects.

For clinicians, to translate the HIV-1 DNA test result into a prognostic prediction of certain ART is intriguing, especially when the HIV-1 viral load remains undetectable. Our previous study has shown that after 96 weeks' ART, low HIV-1 DNA level is significantly associated with higher CD4/CD8 ratio [19]. However, baseline factors that predict low total HIV-1 DNA level in chronic patients after treatment remain elusive.

As such, in this study, we included 490 chronically HIV-1-infected treatment-naïve patients enrolled in multicenter HIV-1 cohort studies [20-22] and 117 outpatients in China. For the first time, a statistical model predicting the possibility of achieving a low total HIV-1 DNA outcome $\left(<100\right.$ copies $/ 10^{6}$ PBMCs) for patients with chronic HIV-1 infection under suppressive cART was derived and validated in two independent cohorts.

\section{Methods}

\section{Subjects}

The Institutional Review Board of the Peking Union Medical College Hospital approved this study, and written informed consents were obtained from all the study participants. All methods were performed in accordance with the relevant guidelines and regulations. This study consists of two sets of study populations: 490 China AIDS Clinical Trial (CACT) participants and 117 outpatients from Peking Union Medical College Hospital (PUMCH).

The 490 CACT participants were included from two previously established multicenter cohorts, Cohort-2009 (CACT0810, ClinicalTrials.gov, identifier NCT00872417, recruited in 2009, followed up for 288 weeks) [20, 21] and Cohort-2012 (CACT1215, ClinicalTrials.gov, identifier NCT01844297, recruited in 2012, followed up for 144 weeks) [22]. Those 490 patients were selected as the training cohort for developing the predictive model of total HIV-1 DNA. The inclusion criteria of the 490 participants were: (1) chronically HIV-1-infected adult; (2) treatment-naïve; (3) CD4 cell count $\leq 350$ cells $/ \mu \mathrm{L}$ in the Cohort-2009 and $\leq 500$ cells $/ \mu \mathrm{L}$ in the Cohort-2012. All subjects received a standard treatment regimen containing two types of nucleoside and nucleotide reverse transcriptase inhibitors and one non-nucleoside reverse transcriptase inhibitor [20-22]. The criteria for successful HIV-1 plasma RNA suppression: (1) HIV-1 plasma RNA were suppressed to $<50$ copies $/ \mathrm{mL}$ within 48 weeks post initiation of cART, (2) transient viremia with $<200$ copies/mL at no more than one time-point during cART was allowed.

In addition, another cohort consists of 117 HIV-1infected adult outpatients, who were successfully treated (treatment was the same as CACT patients) between 2009 to 2016 at PUMCH and followed up for more than 96 weeks, was used as an independent validation cohort. The inclusion criteria for both the training and validation cohorts were: (1) complete baseline characteristics including age, gender, transmission route, and subtype, CD4+ and CD8+ T cell count, and HIV-1 plasma RNA levels; (2) total HIV-1 DNA levels must be available at baseline and week 96, while for other time points of 12 $\mathrm{w}, 24 \mathrm{w}$, and $48 \mathrm{w}$, only less than 2 missing values were allowed; (3) baseline total HIV-1 DNA level $\geq 100$ copies $/ 10^{6}$ PBMCs; and (4) Successful HIV-1 plasma RNA suppression within week 48 .

\section{Total HIV-1 DNA quantitation}

Total HIV-1 DNA was extracted from peripheral blood containing 0.25-1 million PBMCs using the Qiagen QIAsymphony DNA Mini Kit (QIAGEN, Hilden, Germany). The SUPBIO total HIV-1 DNA Quantitative PCR Kit (SUPBIO, Guangzhou, China) was used for 
simultaneously quantitating total HIV-1 DNA and cell number, following the manufacturer's instructions. The linear quantification range of the SUPBIO total HIV-1 DNA quantitative kit was 20 copies $/ 10^{6}$ PBMCs to 100 , 000 copies $/ 10^{6}$ PBMCs.

\section{Statistical methods}

Total HIV-1 DNA and RNA values were log-transformed in all inferential analyses. Generalized linear models of the longitudinal data using a generalized estimating equation (GEE) were performed to select the factors that predict the binary treatment outcome-total HIV-1 DNA $<100$ copies $/ 10^{6}$ PBMCs at week 96 . Logistic regression models were used to characterize how the binary treatment outcome can be predicted by the baseline values of factors identified as a significant predictor in the final GEE model. The receiver operating characteristic (ROC) curve was utilized to evaluate the performance of the prediction power of the logistic regression model in the training set. The software packages SPSS 22.0 (IBM Corporation, Armonk, New York, USA) and MATLAB (R2014a, MathWorks, Natick, MA) were used for data analyses. A $P$ value of $<$ 0.05 was considered statistically significant.

\section{Results}

\section{Baseline characteristics}

Baseline characteristics were summarized for both the training $(n=490)$ and validation $(n=117)$ cohorts in Table 1 . For the training cohort, the majority of patients were aged $30-40$ years, male (69.8\%), infected via sexual transmission [men who have sex with men (MSM) $31.4 \%$, heterosexual 52.7\%], and infected by the CRF01_ AE subtype (44.5\%). The median CD4+ T cell count was 226 cells $/ \mu \mathrm{L}$ and median CD4/CD8 ratio was 0.25 . The median HIV-1 plasma RNA level was $4.66 \log _{10}$ copies/ $\mathrm{mL}$, and median total HIV-1 DNA was $3.00 \log _{10}$ copies $/ 10^{6}$ PBMCs. For the validation cohort, the majority were male $(92.3 \%)$ and $71.8 \%$ of them were MSM. However, the clinical characteristics, including $\mathrm{CD} 4+$ and CD8+ T cell counts and HIV DNA levels, were similar between the two cohorts.

\section{Total HIV-1 DNA decay during 288 weeks of cART}

During 288 weeks of cART, total HIV-1 DNA levels rapidly decreased from a median value of $3.00 \log _{10}$ copies/ $10^{6}$ PBMCs at baseline to $2.55 \log _{10}$ copies $/ 10^{6}$ PBMCs at week $24(P<0.001$, Fig. 1$)$, then leveled off near the level of $2.55 \log _{10}$ copies $/ 10^{6}$ PBMCs during weeks 24 to

Table 1 Patients' characteristics at baseline

\begin{tabular}{|c|c|c|}
\hline Characteristics & Training cohort $(n=490)$ & Validation cohort $(n=117)$ \\
\hline Median age (years, IQR) & $35(28-44)$ & $32(28-43)$ \\
\hline \multicolumn{3}{|l|}{ Gender (n, \%) } \\
\hline Male & $342(69.8)$ & $108(92.3)$ \\
\hline Female & $148(30.2)$ & $9(7.7)$ \\
\hline \multicolumn{3}{|l|}{ Transmission category (n, \%) } \\
\hline MSM & $154(31.4)$ & $84(71.8)$ \\
\hline Heterosexual & $258(52.7)$ & $18(15.4)$ \\
\hline Bisexual & $14(2.9)$ & $4(3.4)$ \\
\hline Blood & $7(1.4)$ & $0(0)$ \\
\hline Others/Unknown & 57 (11.6) & $11(9.4)$ \\
\hline Subtype (n, \%) & & NA \\
\hline CRF01_AE & $218(44.5)$ & \\
\hline C/CRF07_BC/CRF08_BC & $123(25.1)$ & \\
\hline$B / B^{\prime}$ & $55(11.2)$ & \\
\hline URF & $18(3.7)$ & \\
\hline Unknown & $76(15.5)$ & \\
\hline 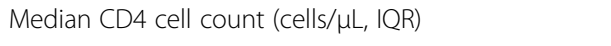 & $226(159-344)$ & $189(50-293)$ \\
\hline 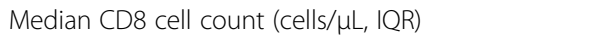 & $809(590-1181)$ & 627 (449-925) \\
\hline Median CD4/CD8 ratio (IQR) & $0.25(0.18-0.40)$ & $0.27(0.13-0.45)$ \\
\hline Median HIV-1 plasma RNA (log copies/mL, IQR) & $4.66(4.34-5.14)$ & $4.48(2.90-4.96)$ \\
\hline Median total HIV-1 DNA (log copies/106 PBMCs, IQR) & $3.00(2.66-3.33)$ & $3.01(2.74-3.29)$ \\
\hline
\end{tabular}

Note: IQR interquartile range, MSM men who have sex with men, NA not applicable, CRF circulating recombinant form, PBMCs peripheral blood mononuclear cells 


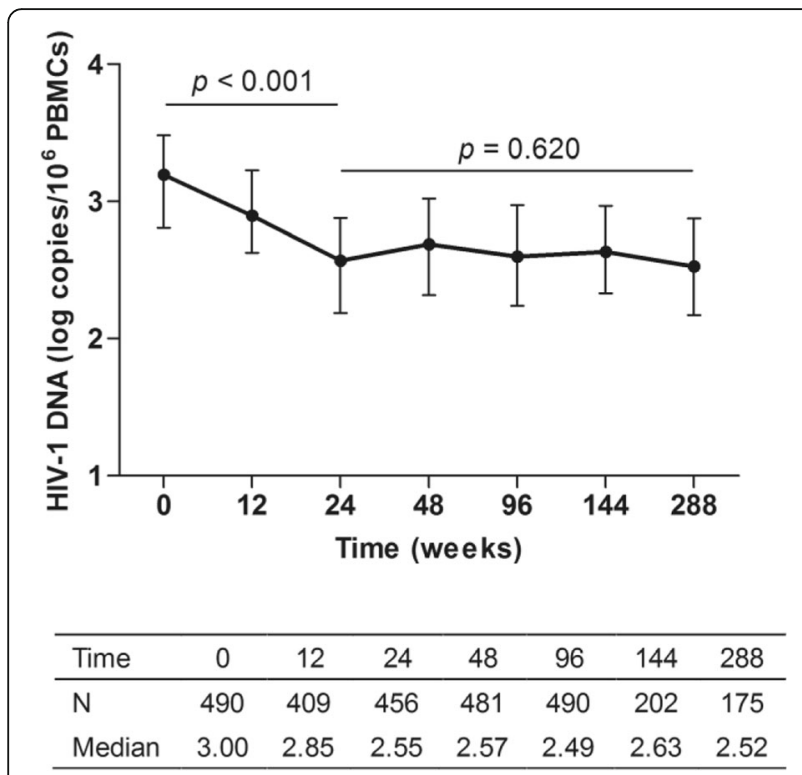

Fig. 1 Decay of total HIV-1 DNA during 288 weeks of CART. N, Number of patients; Mean, the mean value of HIV-1 DNA at each follow-up time point; SD, standard deviation
$288(P=0.620$, Fig. 1$)$. In the following study, we consider the total HIV-1 DNA value at week 96, when all 490 patients had HIV-1 DNA data, as the HIV-1 DNA outcome after cART.

\section{Contribution of baseline factors to the total HIV-1 DNA decay}

After 96 weeks of treatment, 18.8\% (92/490) of subjects achieved total HIV-1 DNA levels of $<100$ copies $/ 10^{6}$ PBMCs. To identify which factors were associated with low HIV-1 DNA levels after 96 weeks of ART, univariate and multivariate logistic regression were used for the analysis. Univariate logistic regression revealed that a lower baseline total HIV-1 DNA level $(\mathrm{RR}=0.07$ per 1 $\log _{10}$ copies $/ 10^{6}$ PBMCs, $\left.P<0.001\right)$ and a higher baseline CD4+ T-cell count $(\mathrm{RR}=2.11$ per 100 cells $/ \mu \mathrm{L}$ increase, $P=0.003)$ were beneficial factors associated with lower HIV-1 DNA levels at week 96 (Table 2). Consistently, in the multivariate logistic regression analysis, baseline factors predicting total HIV-1 DNA $<100$ copies $/ 10^{6}$ PBMCs at week 96 were also total HIV-1 DNA $(\mathrm{RR}=$ 0.08 per $1 \log _{10}$ copies $/ 10^{6}$ PBMCs, $\left.P<0.001\right)$ and $C D 4+$ $\mathrm{T}$ cell count $(\mathrm{RR}=1.72$ per 100 cells $/ \mu \mathrm{L}$ increase, $P<$ 0.001) (Table 2).

Table 2 Baseline factors associated with total HIV-1 DNA reduction to 100 copies $/ 10^{6}$ PBMC level

\begin{tabular}{|c|c|c|c|c|}
\hline \multirow[t]{2}{*}{ Variables } & \multicolumn{2}{|c|}{ Univariate Analysis } & \multicolumn{2}{|c|}{ Multivariate Analysis } \\
\hline & $\mathrm{RR}(95 \% \mathrm{Cl})$ & $P$ & RR $(95 \% \mathrm{Cl})$ & $P$ \\
\hline Sex & & 0.921 & & 0.921 \\
\hline Male & 1 & & 1 & \\
\hline Female & $0.96(0.46-2.04)$ & & $0.96(0.46-2.04)$ & \\
\hline Age-per 10 years increase & $1.02(0.76-1.37)$ & 0.891 & $1.02(0.76-1.37)$ & 0.889 \\
\hline Transmission route & & 0.359 & & 0.305 \\
\hline MSM & 1 & & 1 & \\
\hline Heterosexual & $1.06(0.49-2.30)$ & 0.885 & $1.15(0.62-2.13)$ & 0.650 \\
\hline Bisexual & $0.24(0.03-2.19)$ & 0.203 & $0.27(0.03-2.39)$ & 0.241 \\
\hline Blood & $1.33(0.10-17.37)$ & 0.826 & $0.85(0.08-8.97)$ & 0.895 \\
\hline Others/Unknown & $0.35(0.09-1.41)$ & 0.140 & $0.35(0.09-1.31)$ & 0.120 \\
\hline Subtype & & 0.549 & & 0.550 \\
\hline CRF01_AE & 1 & & 1 & \\
\hline C/CRF07_BC/CRF08_BC & $1.47(0.75-2.86)$ & 0.264 & $1.47(0.75-2.86)$ & 0.263 \\
\hline$B / B^{\prime}$ & $0.71(0.23-2.21)$ & 0.557 & $0.72(0.23-2.22)$ & 0.562 \\
\hline Others/Unknown & $1.12(0.31-4.01)$ & 0.863 & $1.12(0.31-4.00)$ & 0.864 \\
\hline Baseline total HIV-1 DNA -per 1 log copies $/ 10^{6}$ PBMCs & $0.07(0.03-0.16)$ & $<0.001$ & $0.08(0.04-0.16)$ & $<0.001$ \\
\hline Baseline HIV-1 plasma RNA-per 1 log copies/mL & $1.20(0.74-1.96)$ & 0.463 & $1.12(0.70-1.77)$ & 0.641 \\
\hline Baseline CD4 cell count-per 100 cells/ $\mathrm{LL}$ & $2.11(1.28-3.48)$ & 0.003 & $1.72(1.35-2.20)$ & $<0.001$ \\
\hline Baseline CD8 cell count-per 100 cells/ $/ \mathrm{L}$ & $0.92(0.81-1.05)$ & 0.211 & $0.97(0.90-1.04)$ & 0.389 \\
\hline Baseline CD4/CD8 ratio-per 0.1 increase & $0.87(0.64-1.19)$ & 0.391 & $0.86(0.63-1.17)$ & 0.340 \\
\hline
\end{tabular}

$R R$ relative risk, $C l$ confidence interval, $M S M$ men who have sex with men, $C R F$ circulating recombinant form, $P B M C s$ peripheral blood mononuclear cells 
Statistical model based on baseline DNA and CD4+ T cells to predict total HIV-1 DNA under CART

Further, generalized estimating equations (GEE) and logistic regression methods were used to derive a predictive model of total HIV- 1 DNA $<100$ copies $/ 10^{6}$ PBMCs after 96 weeks of cART. With the GEE analysis, we found that longitudinal total HIV-1 DNA, CD4+ T cells, and $\mathrm{CD} 4 / \mathrm{CD} 8$ ratio values were correlated with the total HIV-1 DNA outcome (Supplementary Table S1). Univariate and multivariate logistic regression analyses were then performed to relate the binary outcome with each identified predictor and combinations thereof. Total HIV-1 DNA and CD4 count were screened out as significant predictors of the treatment outcome of total HIV-1 DNA. Interestingly, the highest area under the ROC curve (AUC) of 0.82 was observed in the multivariate model with baseline total HIV-1 DNA and CD4 count other than each univariate model (Fig. 2A). As such, the best-performed predictive model based on baseline total HIV-1 DNA and CD4 count was derived:

$\operatorname{logit}(\theta)=4.579-2.518 \times \mathrm{DNA}+0.477 \times \mathrm{CD} 4$ (Eq. 1$)$.

Where $\theta$ represents the probability of achieving total HIV-1 DNA $<100$ copies $/ 10^{6}$ PBMCs at week 96 postcART; DNA represents the baseline total HIV-1 DNA level in $\log _{10}$ copies $/ 10^{6}$ PBMCs; and CD4 represents the baseline CD4+ T cell count in 100 cells $/ \mu \mathrm{L}$. For example, if a patient starts cART treatment with $300\left(2.48 \log _{10}\right)$ copies $/ 10^{6}$ PBMCs of baseline total HIV-1 DNA and a CD4 count of 500 cells $/ \mu \mathrm{L}$, there is a $72 \%(\theta=0.72)$ chance that his total HIV-1 DNA will fall below 100 copies $/ 10^{6}$ PBMCs after 96 weeks of treatment according to eq. 1.
With Eq. 1, we validated the prediction model with the validation cohorts, which contained 117 outpatients from the real hospital settings. At cutoff 2, the greatest true positive rate (TPR) and false positive rate (FPR) distance, the predictive model performed similarly in both training and validation cohorts. TPRs were 83.70 and $75.00 \%$ while FTRs were 29.40 and $30.48 \%$ in the training and validation cohorts, respectively (Fig. 2B). In this independent cohort of 117 patients, this model achieved a sensitivity of $75.00 \%$ and specificity of $69.52 \%$.

\section{Discussion}

In this study, the characteristics and impact factors of HIV-1 DNA decay was studied with longitudinal cohorts. A probability model that predicts the outcome of HIV-1 DNA reservoir size after 2 years of cART using baseline values of total HIV-1 DNA and CD4+ T cell count was established for the first time. The model performed well and similarly in both the training cohort and an independent outpatient validation cohort, which indicated the robustness of the model.

Globally, most HIV-1 patients on treatment are chronically infected. Achieving remission or a potential functional cure in such patients is more challenging than in those who are acutely infected [10, 12]. Studies of the HIV-1 reservoir in chronic patients were limited by small populations or were cross-sectional [18, 23, 24]. To our knowledge, the data in the present study represent the largest longitudinal cohort study focusing on chronically HIV-1-infected individuals. We found that for chronically HIV-1-infected patients, total HIV-1 DNA decay after initiation of cART demonstrated a
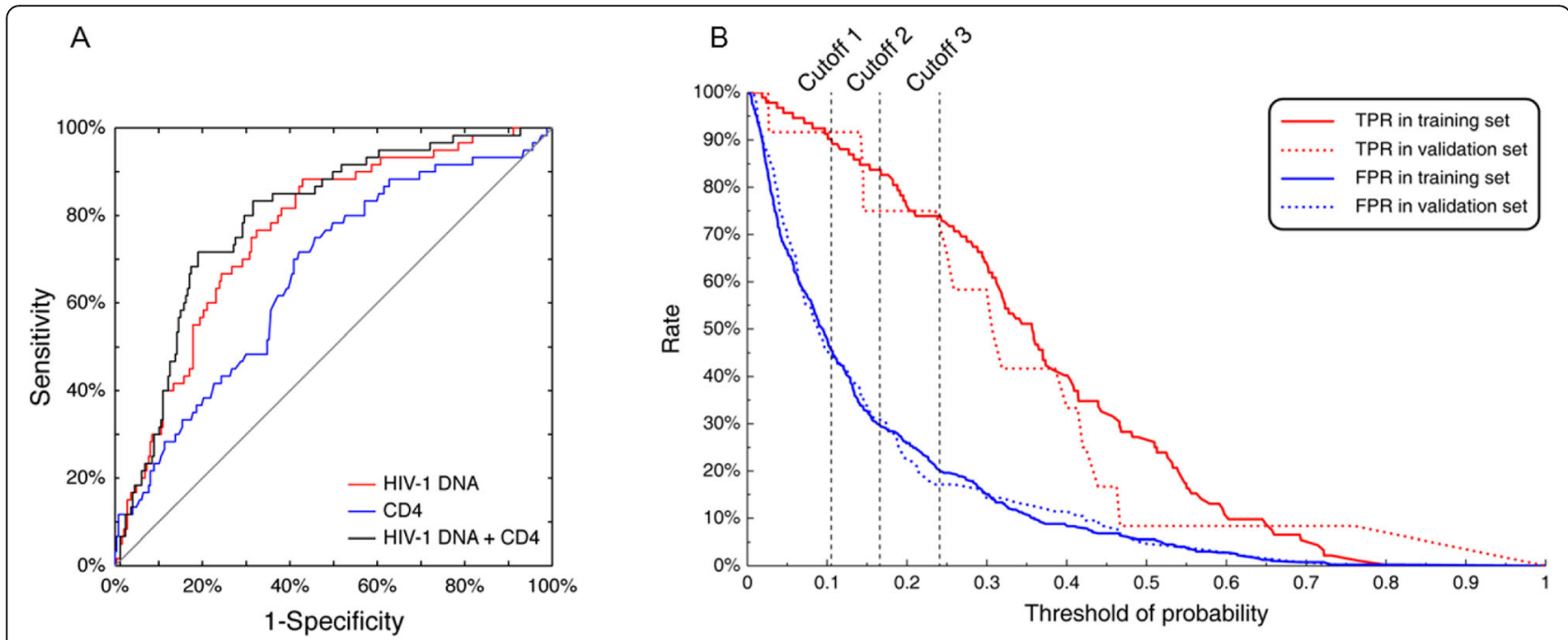

Fig. 2 Total HIV-1 DNA prediction model. A ROC curves of different prediction models in the training cohort. B True positive rate (TPR, red) and False positive rate (FPR, blue) performance of the model in the training (solid lines) and the validation cohorts (dotted lines) with different cutoffs. Cutoff 1, the lowest threshold to obtain a TPR greater than 90\%; Cutoff 2, the greatest TPR and FPR distance; Cutoff 3, the smallest threshold to obtain an FPR less than 20\% 
biphasic reduction within 96 weeks. Most decline happened in the first 6 months and then began to plateau, which was consistent with other findings in chronically HIV-1-infected patients [25, 26]. Compared with the studies by Besson et al. [25] and Gandhi et al. [27], our sample size was larger, and we detected the HIV-1 DNA at week 12 and 24 . We suggested for the first time that the HIV-1 DNA decline was mainly within 24 weeks rather than 48 weeks ( 1 year). In addition, Gandhi et al. found that there was a positive correlation between the level of HIV-1 DNA before treatment and on treatment. Our study further confirmed that baseline HIV-1 DNA was an independent predictive factor of HIV-1 DNA after 2 years of treatment. Furthermore, $18.8 \%$ of chronic patients achieved $<100$ total HIV-1 DNA copies $/ 10^{6}$ PBMCs after 96 weeks of cART. In comparison, with prolonged treatment as long as the median duration of 13 years, it was reported that $28 \%$ of such patients could achieve $\sim 150$ total HIV-1 DNA copies $/ 10^{6}$ PBMCs [18].

Our data showed that the pre-treatment total HIV-1 DNA burden and CD4+ T cell count correlate to long term total HIV-1 DNA control in real hospital settings. This model could be applicable for clinical decisionmaking on therapy strategies. Our findings suggest that chronically infected patients initiating cART with lower total HIV-1 DNA and higher CD4+ T cell baseline levels have a higher possibility of achieving low total HIV-1 DNA level with effective cART. In 2016, HIV-1 DNA has been used as one of the criteria for screening subjects in treatment-interruption study by Calin et al. [28]. In future studies such as treatment-interruption, deescalation therapy, or cell or gene therapy, clinicians could select suitable subjects who may benefit more by preliminary prediction of HIV-1 DNA outcome prior to patients' initial treatment. This study also supports initiatives for early treatment. Although delayed treatments can also keep viral plasma RNA within the detection limits, they maintain high DNA levels.

One limitation existed in our study was that we did not account for other possible mechanisms contributing to total HIV-1 DNA decay, including duration of infection, antibody responses [29], and polyfunctionality of HIV-1-specific T cells [30]. These present interesting directions for future hypothesis-driven investigations. In addition, the predictive model was established based on specific HIV-1 DNA testing methods and specific populations. The results of the study necessitate further verification in different settings and with different methods.

\section{Conclusions}

In summary, this is a longitudinal study in a large population of chronically HIV-1-infected patients to evaluate the predictive factors associated with total HIV-1 DNA decay after cART. Based on baseline total HIV-1 DNA and CD4, we established a predictive model for treatment-naïve patients to estimate their likelihood of achieving total HIV-1 DNA $<100$ copies $/ 10^{6}$ PBMCs after suppressive cART. This model will be applicable for identifying potential cART-cessation candidates who are relatively more likely to achieve functional cure before cART initiation.

\begin{abstract}
Abbreviations
CART: Combined antiretroviral therapy; PBMCs: Peripheral blood mononuclear cells; RR: Risk ratio; STI: Structured treatment interruption; PTCs: Post-treatment controllers; CACT: China AIDS Clinical Trial; PUMCH: Peking Union Medical College Hospital; GEE: Generalized estimating equation; ROC: Receiver operating characteristic; MSM: Men who have sex with men; AUC: Area under the ROC curve; TPR: True positive rate; FPR: False positive rate; IQR: Interquartile range; NA: Not applicable; CRF: Circulating recombinant form; Cl: Confidence interval
\end{abstract}

\section{Supplementary Information}

The online version contains supplementary material available at https://doi. org/10.1186/s12879-021-06267-5.

Additional file 1: TableS1. Generalized Estimating Equation results of single factor/covariate.

\begin{abstract}
Acknowledgements
We thank Jiangning Li for editorial assistance, Chunmei Peng and Keji Deng for technical support to quantify HIV-1 DNA. We thank Can Yuan, Cong Yu and Andrew Meuser for language polishing. We thank all the subjects and staff in the original parent studies for their participation: Shanghai Public Health Clinical Center; Guangzhou Eighth People's Hospital, Guangzhou Medical University; Beijing You'an Hospital, Capital Medical University; The First Affiliated Hospital, China Medical University; Beijing Ditan Hospital, Capital Medical University; Yunnan AIDS Care Center; Mengchao Hepatobiliary Hospital of Fujian Medical University; The Third People's Hospital of Shenzhen; Tangdu Hospital, The Fourth Military Medical University; The People's Hospital of Nanning; Longtan Hospital of Guangxi Zhuang Autonomous Region; The First Hospital of Changsha; Public Health Clinical Center of Chengdu; Dehong People's Hospital; The People's Hospital of Luzhai; The People's Hospital of Du'an County; 302 Military Hospital; The Key Laboratory of Infection and Immunity, Institute of Biophysics, Chinese Academy of Sciences.
\end{abstract}

\section{Authors' contributions}

Conceived and designed the experiments: TSL. Performed the experiments: YSY, NDW, YH, TZ. Recruitment, compliance education, and follow-up of the patients: YH, TZ, WC, WL, JX, XJS, YLL. Collected the clinical data: YSY, NDW, WC, WL, JX, XJS, YLL. Analyzed the clinical data: YJL, YZC, TW, YDH and YSY. Wrote the paper: YJL, TW, NDW, TFZ and YSY. Rigorously reviewed the manuscript: TSL, YDH and TFZ. The author(s) read and approved the final manuscript.

\section{Funding}

This work was supported by the National Science and Technology Major Project of China for the 13th Five-year Plan (2017ZX10202101-001 to TSL, 2018ZX10732101-002 to TW), the CAMS Innovation Fund for Medical Sciences (CAMS-12M-1-014 to TSL), the 12th Five-Year Major New Drug Discovery Science and Technology (2012ZX09303013 to TW), and the Key Project for Research and Development of Guangdong province (2016B020238002 to TW). The funders had no role in study design, data collection, data analyses, preparation of the manuscript, or decision to publish.

\section{Availability of data and materials}

The datasets used and/or analyzed in the current study are available from the corresponding author on reasonable request. 


\section{Declarations}

\section{Ethics approval and consent to participate}

The Ethical Committee of Peking Union Medical College Hospital approved this study and all participants provided written informed consent

\section{Consent for publication}

Not applicable.

\section{Competing interests}

The authors declare that they have no competing interests to disclose.

\section{Author details}

'Department of Infectious Diseases, Peking Union Medical College Hospital, Chinese Academy of Medical Sciences \& Peking Union Medical College, No. 1 Shuaifuyuan, Wangfujing Street, Beijing 100730, China. ${ }^{2}$ Center for AIDS Research, Chinese Academy of Medical Sciences \& Peking Union Medical College, Beijing, China. ${ }^{3}$ Department of Infectious Diseases and Clinical Microbiology, Beijing Chao-yang Hospital, Capital Medical University, Beijing China. ${ }^{4}$ Division of Infectious Diseases, Massachusetts General Hospital and Brigham and Women's Hospital, Harvard Medical School, Boston, MA, USA. ${ }^{5}$ Key Laboratory of Functional Protein Research of Guangdong Higher Education Institutes, Institute of Life and Health Engineering, College of Life Science and Technology, Jinan University, Guangzhou 510632, China. ${ }^{6}$ Vaccine and Infectious Disease Division, Fred Hutchinson Cancer Research Center, Seattle, WA, USA. ${ }^{7}$ Department of Global Health, University of Washington, Seattle, WA, USA. ${ }^{8}$ Department of Laboratory Medicine, School of Medicine, University of Washington, 325 Ninth Ave, Seattle, WA 98104-2499, USA.

\section{Received: 8 October 2020 Accepted: 2 June 2021}

\section{Published online: 22 June 2021}

\section{References}

1. Margolis DM, Garcia JV, Hazuda DJ, Haynes BF. Latency reversal and viral clearance to cure HIV-1. Science. 2016;353(6297):aaf6517.

2. Falcinelli SD, Ceriani C, Margolis DM, Archin NM. New Frontiers in measuring and characterizing the HIV reservoir. Front Microbiol. 2019;10: 2878. https://doi.org/10.3389/fmicb.2019.02878

3. Bashiri K, Rezaei N, Nasi M, Cossarizza A. The role of latency reversal agents in the cure of HIV: a review of current data. Immunol Lett. 2018;196:135-9. https://doi.org/10.1016/j.imlet.2018.02.004.

4. Avettand-Fenoel V, Hocqueloux L, Ghosn J, Cheret A, Frange P, Melard A, et al. Total HIV-1 DNA, a marker of viral reservoir dynamics with clinical implications. Clin Microbiol Rev. 2016;29(4):859-80. https://doi.org/10.1128/ CMR.00015-16.

5. Goujard C, Bonarek M, Meyer L, Bonnet F, Chaix ML, Deveau C, et al. CD4 cell count and HIV DNA level are independent predictors of disease progression after primary HIV type 1 infection in untreated patients. Clin Infect Dis. 2006;42(5):709-15. https://doi.org/10.1086/500213.

6. Shiramizu B, Williams AE, Shikuma C, Valcour V. Amount of HIV DNA in peripheral blood mononuclear cells is proportional to the severity of HIV-1associated neurocognitive disorders. J Neuropsychiatry Clin Neurosci. 2009; 21(1):68-74. https://doi.org/10.1176/jnp.2009.21.1.68.

7. Killebrew DA, Troelstrup D, Shiramizu B. Preferential HIV-1 integration sites in macrophages and HIV-associated malignancies. Cell Mol Biol (Noisy-legrand). 2004;50 Online Pub:OL581-9.

8. Williams JP, Hurst J, Stohr W, Robinson N, Brown H, Fisher M, et al. HIV-1 DNA predicts disease progression and post-treatment virological control. Elife. 2014;3:e03821. https://doi.org/10.7554/eLife.03821.

9. Spivak AM, Planelles V. HIV-1 eradication: early trials (and tribulations). Trends Mol Med. 2016;22(1):10-27. https://doi.org/10.1016/j.molmed.2015.11.004

10. Li JZ, Etemad B, Ahmed H, Aga E, Bosch RJ, Mellors JW, et al. The size of the expressed HIV reservoir predicts timing of viral rebound after treatment interruption. AIDS. 2016;30(3):343-53. https://doi.org/10.1097/QAD. 0000000000000953.

11. Persaud D, Gay H, Ziemniak C, Chen YH, Piatak M Jr, Chun TW, et al. Absence of detectable HIV-1 viremia after treatment cessation in an infant. N Engl J Med. 2013;369(19):1828-35. https://doi.org/10.1056/ NEJMoa1302976.
12. Saez-Cirion A, Bacchus C, Hocqueloux L, Avettand-Fenoel V, Girault I, Lecuroux C, et al. Post-treatment HIV-1 controllers with a long-term virological remission after the interruption of early initiated antiretroviral therapy ANRS VISCONTI study. PLoS Pathog. 2013;9(3):e1003211. https://doi. org/10.1371/journal.ppat.1003211.

13. Frange $\mathrm{P}$, Faye $\mathrm{A}$, Avettand-Fenoel V, Bellaton $\mathrm{E}$, Descamps $\mathrm{D}$, Angin $\mathrm{M}$, et al. HIV-1 virological remission lasting more than 12 years after interruption of early antiretroviral therapy in a perinatally infected teenager enrolled in the French ANRS EPF-CO10 paediatric cohort: a case report. Lancet HIV. 2016;3(1):e49-54. https://doi.org/10.1016/S2352-3018(15)00232-5.

14. Laanani M, Ghosn J, Essat A, Melard A, Seng R, Gousset M, et al. Impact of the timing of initiation of antiretroviral therapy during primary HIV-1 infection on the decay of cell-associated HIV-DNA. Clin Infect Dis. 2015; 60(11):1715-21. https://doi.org/10.1093/cid/civ171.

15. Chéret A, Nembot G, Mélard A, Lascoux C, Slama L, Miailhes $P$, et al, Intensive five-drug antiretroviral therapy regimen versus standard tripledrug therapy during primary HIV-1 infection (OPTIPRIM-ANRS 147): a randomised, open-label, phase 3 trial. Lancet Infect Dis. 2015;15(4):387-96. https://doi.org/10.1016/S1473-3099(15)70021-6.

16. Ostrowski M, Benko E, Yue FY, Kim CJ, Huibner S, Lee T, et al. Intensifying antiretroviral therapy with raltegravir and maraviroc during early human immunodeficiency virus (HIV) infection does not accelerate HIV reservoir reduction. Open Forum Infect Dis. 2015;2(4):ofv138.

17. Hocqueloux L, Avettand-Fenoel V, Jacquot S, Prazuck T, Legac E, Melard A et al. Long-term antiretroviral therapy initiated during primary HIV-1 infection is key to achieving both low HIV reservoirs and normal T cell counts. J Antimicrob Chemother. 2013;68(5):1169-78. https://doi.org/10.1 093/jac/dks533.

18. Cuzin L, Pugliese P, Saune K, Allavena C, Ghosn J, Cottalorda J, et al. Levels of intracellular HIV-DNA in patients with suppressive antiretroviral therapy. AIDS. 2015;29(13):1665-71. https://doi.org/10.1097/QAD.0000000000000723.

19. Yue Y, Wang N, Han Y, Zhu T, Xie J, Qiu Z, et al. A higher CD4/CD8 ratio correlates with an ultralow cell-associated HIV-1 DNA level in chronically infected patients on antiretroviral therapy: a case control study. BMC Infect Dis. 2017;17(1):771. https://doi.org/10.1186/s12879-017-2866-y.

20. Luo L, Zeng Y, Li T, Lv W, Wang H, Guo F, et al. Prospective echocardiographic assessment of cardiac structure and function in Chinese persons living with HIV. Clin Infect Dis. 2014;58(10):1459-66. https://doi. org/10.1093/cid/ciu086.

21. Li Y, Gu L, Han Y, Xie J, Wang H, Lv W, et al. HIV-1 subtype B/B' and baseline drug resistance mutation are associated with virologic failure: a multicenter cohort study in China. J Acquir Immune Defic Syndr. 2015;68(3):289-97. https://doi.org/10.1097/QAl.0000000000000473.

22. Xie J, Han Y, Qiu Z, Li Y, Li Y, Song X, et al. Prevalence of hepatitis B and C viruses in HIV-positive patients in China: a cross-sectional study. J Int AIDS Soc. 2016;19(1):20659. https://doi.org/10.7448/IAS.19.1.20659.

23. Burgard M, Boufassa F, Viard JP, Garrigue I, Ruffault A, lzopet J, et al. Factors influencing peripheral blood mononuclear cell-associated HIV-1 DNA level after long-term suppressive antiretroviral therapy in 236 patients. AIDS. 2009;23(16):2165-71. https://doi.org/10.1097/QAD.0b013e32833032d4.

24. Chun TW, Justement JS, Pandya P, Hallahan CW, McLaughlin M, Liu S, et al. Relationship between the size of the human immunodeficiency virus type 1 (HIV-1) reservoir in peripheral blood CD4+ T cells and CD4+:CD8+ T cell ratios in aviremic HIV-1-infected individuals receiving long-term highly active antiretroviral therapy. J Infect Dis. 2002;185(11):1672-6. https://doi. org/10.1086/340521.

25. Besson GJ, Lalama CM, Bosch RJ, Gandhi RT, Bedison MA, Aga E, et al. HIV-1 DNA decay dynamics in blood during more than a decade of suppressive antiretroviral therapy. Clin Infect Dis. 2014;59(9):1312-21. https://doi.org/10.1 093/cid/ciu585

26. Uprety P, Patel K, Karalius B, Ziemniak C, Chen YH, Brummel SS, et al. Human immunodeficiency virus type 1 DNA decay dynamics with early, long-term Virologic control of perinatal infection. Clin Infect Dis. 2017;64(11): 1471-8. https://doi.org/10.1093/cid/cix192.

27. Gandhi RT, McMahon DK, Bosch RJ, Lalama CM, Cyktor JC, Macatangay BJ, et al. Levels of HIV-1 persistence on antiretroviral therapy are not associated with markers of inflammation or activation. PLoS Pathog. 2017;13(4): e1006285. https://doi.org/10.1371/journal.ppat.1006285.

28. ULTRASTOP StudyCalin R, Hamimi C, Lambert-Niclot S, Carcelain G, Bellet J, Assoumou L, et al. Treatment interruption in chronically HIV-infected patients with an ultralow HIV reservoir. AIDS. 2016;30(5):761-9. 
29. Stephenson KE, Neubauer GH, Bricault CA, Shields J, Bayne M, Reimer U, et al. Antibody responses after analytic treatment interruption in human immunodeficiency virus-1-infected individuals on early initiated antiretroviral therapy. Open Forum Infect Dis. 2016:3(2):ofw100.

30. Samri A, Bacchus-Souffan C, Hocqueloux L, Avettand-Fenoel V, Descours B Theodorou I, et al. Polyfunctional HIV-specific T cells in post-treatment controllers. AIDS. 2016;30(15):2299-302. https://doi.org/10.1097/QAD. 0000000000001195 .

\section{Publisher's Note}

Springer Nature remains neutral with regard to jurisdictional claims in published maps and institutional affiliations.

Ready to submit your research? Choose BMC and benefit from:

- fast, convenient online submission

- thorough peer review by experienced researchers in your field

- rapid publication on acceptance

- support for research data, including large and complex data types

- gold Open Access which fosters wider collaboration and increased citations

- maximum visibility for your research: over $100 \mathrm{M}$ website views per year

At $\mathrm{BMC}$, research is always in progress.

Learn more biomedcentral.com/submissions 